\title{
Hub-And-Spoke Airlines Versus Low-Cost Airlines And Price Discrimination
}

Recai Aydin, Turkish National Police Academy, Turkey

Roger Morefield, University of Saint Thomas, USA

\begin{abstract}
The purpose of this study is to examine the impact of the continuing trend in the U.S. Airline industry away from hub-and-spoke (network) airlines and toward low-cost airlines. The model of this study examines the level of success which the network carriers may experience by using market segmentation and price discrimination to sustain profitability in the face of the growth in market share held by low-cost carrier airlines.
\end{abstract}

Keywords: airline industry, price discrimination, industrial organization, air carriers, hub-and-spoke

\section{INTRODUCTION}

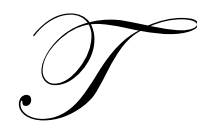

he purpose of this study is to explain how and why the major air carriers practiced price discrimination in the U.S airline industry after deregulation, even though there was a threat of entry and underpricing by low-cost carriers. Since effective competition in the industry is between all airlines flying between a pair of cities, a city-pair fare comparison is helpful in illustrating price dispersion among carriers. Airline fare structures are complex and include a broad variety of prices. Although the degree of price discrimination has been extensive, major carriers and regional carriers have continued to practice it since airline deregulation was completed in 1985. One of the major consequences of deregulation was the discontinuation of direct flights to many smaller markets. This in turn caused the development of a "hub-and-spoke" system. Smaller markets began to be served by commuter-type flights to connecting flights in major hubs. The major carriers' plan was to use these possibly unprofitable flights from the "spokes" to bring passengers to profitable connecting flights. Their thinking was that this would ensure customer loyalty, thus raising an effective barrier to entry into major markets. But the hub-and-spoke system did not prove to be an effective entry barrier. Low-cost carriers were able to achieve economies of scale by "skimming the cream" from denser routes using fewer aircraft models and offering fewer amenities to passengers. As long as the low-cost carriers had a relatively small market share, they were not a threat to the hub-and-spoke system maintained by the majors. But the hub-and-spoke system's higher costs became increasingly difficult to support as the market share enjoyed by the low-cost carriers rose. Clearly the market has shifted towards low-cost, low-fare airlines, and this trend is further enhanced by a decrease in the number of business travelers and other high-paying customers. There has also been a shift in demand by pleasure travelers, many of whom are now willing to drive two or three hours to smaller or less convenient airports to fly low-fare airlines.

Since 1985, U.S. airlines have had their choice of which routes to fly and what fares to charge. Immediately after 1985, the traditional network carriers were somewhat at a loss, given their long-standing culture of protected routes and fares far exceeding marginal and average costs. Their high-fixed-cost culture required that they fly full, or almost full, planes to survive. At that point, product differentiation strategies became more important than ever. These firms began to segment themselves into "service oriented" and "price driven" divisions in an attempt to increase load factors. Post-deregulation hub-and-spoke airlines have worked to enhance their ability to discriminate on price by creating complex restrictions that force passengers into categories. This resulted in a baffling mix of restrictions which included non-refundable fares, requiring some flights to be booked two or more weeks in advance, and requiring Saturday night stayovers on round-trip flights. This allowed passengers to be segmented into two basic groups: business travelers, and pleasure travelers. Thus the framework was set for discriminating among passengers with low demand elasticity (business travel) and those with a high demand elasticity (pleasure travel). 
Offering discounted fares to passengers with a high price elasticity of demand can sharply increase load factors. Maximizing revenues for a given flight is a challenging and complex task, but by changing ticket prices as the time for departure of the flight approaches, the airlines can achieve higher revenues than with static pricing. Another device that boosts revenues is that of allowing "standby" passengers, as the marginal cost of placing a passenger in an otherwise empty seat is low compared to the additional revenue generated by them.

Discriminatory pricing practices have long been criticized as unfair (Dirlam and Kahn 1952). But only a small fraction of airline passengers is truly negatively affected by price discrimination. Before deregulation a majority of passengers purchased "coach" fares, which were only slightly discounted. The inroads made by low-cost carriers forced the major carriers into some substantial policy changes. Delta Airlines completely restructured its fares and related policies in January 2005. These changes included 6,000 discount programs for corporate groups, sharp reductions in the availability of "walk-up" fares, and discontinuation of "Saturday night stayover" requirements. In those city pairs where they competed directly with Delta, United, Northwest, US Airways and Continental implemented changes to match Delta. American Airlines did not directly match Delta, but made many fare changes and matched Delta to some extent. This type of behavior illustrates the mutual interdependency that exists in oligopoly, especially in this "tight" oligopoly where 3 or 4 carriers fly very similar schedules between the same city pairs.

\section{LITERATURE REVIEW}

Dana (1998) attempted to explain the role of advance purchase discounts as a means of reducing the uncertainty of consumer demand in the airline industry. These discounts for low-valuation customers could perhaps reduce this uncertainty. However, Dana noted that his results could not be obtained by firms which possessed market power, and his model assumed that firms have no market power. He also noted that his model could not successfully explain practices such as "Saturday-night stayover" and other round-trip requirements.

Hayes and Ross (1998) used a price dispersion model to attempt to distinguish between price dispersion and price discrimination. Their strong findings were that significant differences existed between price discrimination and price dispersion among airlines in the early 1990s. Most price dispersion, they found, was associated with peak load pricing schemes and "fare wars," rather than price discrimination.

Stavins' (2001) findings were that the level of price discrimination decreases with market concentration. Following the traditional view, Stavins asserted that price discrimination should not be practiced in perfect competition. In additions, she stressed that price discrimination can be expected to increase with market concentration. Other studies, such as Giamue and Guillou (2003), support Stavins' findings. Giamue and Guillou found a positive correlation between market concentration and price discrimination in European airline markets.

Aydin (2008) focused on the notion that price discrimination alone is not evidence of market power. Therefore the existence of price discrimination in the industry should not be used to justify interventions by regulatory institutions.

\section{MODEL AND IMPLICATIONS}

This study uses the basic model built by Aydin (2008) and assumes a quasi-perfectly competitive environment where consumers have perfect information and firms have identical cost structures and produce identical services. Along with the incumbent, entrants can seize the opportunity if there is a need for an extra flight on a route. Free entry and exit is assumed for any route, and the number of daily flights is determined simply by the ratio of demand to the efficient size of aircraft (hence the number of firms will be related to this ratio).

It is also assumed that total market demand is constant in the short run. It may be useful to explain the competitive conditions in the airline industry, since the short run capacity condition is quite similar in this model to that particular industry. Airlines mostly announce their schedules before the beginning of each period and the schedules are somewhat inflexible, although individual airlines may try to increase flexibility for their own passengers through code sharing and other similar arrangements among airlines. 
Firms are assumed to be able to recognize differences in consumers' preferences. There are three different groups of consumers in the market: $\mathrm{H}$ (high demanders such as business travelers), M (regulars) or L (low demanders such as pleasure travelers). Moreover, the firms can prevent reselling, through restrictions on the tickets. For simplicity, roundtrip travel and other complexities of the real world airline industry are ignored. Utility functions of these groups are given as

$U_{H}=(\beta+s)-p$

$U_{M}=\beta-p$

$U_{L}=(\beta-d)-p$

where $\beta$ is basic utility of a flight for all the consumers, "s" is additional utility from avoiding a required "Saturday night stay" and all other undesirable restrictions of a cheaper ticket while, "d" is the utility loss due to a required "Saturday night stayover", advance purchase requirements, the nonrefundable feature, or other restrictions imposed on low price tickets. I assume that customer distribution will be equal between two firms when they offer identical service at the same price. Each consumer buys only one unit provided that her $U \geq 0$; otherwise (if $U<0$ ) she will not buy any unit.

Marginal Cost is zero and Total Cost is a function not of the number of passengers but of the number of daily flights. Therefore, the cost function is

$T C=C_{C}+\lambda C_{S}$

where $C_{C}$ is common (this may be or may not be sunk) fixed cost per day, $\lambda$ is the number of flights per day in the route by the firm, and $C_{S}$ is avoidable fixed cost per flight (for now also a separate fixed cost). Any airline has two options: (1) uniform pricing by charging an average price that maximizes its profit, or (2) perfect price discrimination by charging $(\beta+s)$ to business travelers, $(\beta)$ to regular passengers, and $(\beta-d)$ to pleasure travelers. If we specify the following conditions in the market, when fixed costs are large enough to limit survival:

$$
(\beta-d) N-C_{C}-C_{S}<0
$$

$\beta\left(n_{H}+n_{M}\right)-C_{C}-C_{S}<0$

Suppose there are two major cities; city A and city B. City A is a hub for firm 1 and city B is a hub for firm 2 (Figure 1). Aydin (2008) suggests that common cost recovery may force network airlines to charge discriminatory prices to collect as much as revenue as possible while increasing their load factors, especially in their spoke connections. How will competing network airlines react in terms of pricing strategy if we introduce a new nonnetwork airline that is only interested in serving passengers between A and B? The new airline has lower cost and price, because it does not have any common cost.

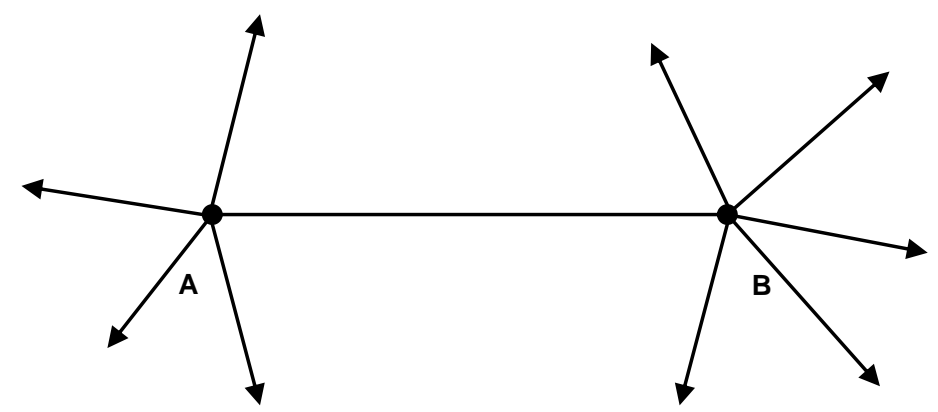

Figure 1 
Suppose the non-network airline charges a uniform price because it aims to increase its load factor only between $\mathrm{A}$ and $\mathrm{B}$. Following the assumptions (1) and (2), the new airline will charge $p=\beta-d$ to attract every potential customer in the market. Condition (1) imposes that this low price would not generate enough revenue to cover the cost of a network carrier, but may generate enough revenue for the low-cost entrant to cover its cost. This could be due to lower total cost in the absence of common cost.

Now we have network carriers that bring connections and convenience to their customers and one low-cost carrier that can serve at a discounted price and can attract price-driven passengers. Some portion of the passengers in each group will still prefer the network carriers, because they need to make some connection on the spokes. The rest (in this setup basically the people who are flying only between A and B) will be or may be indifferent among them. It is worth noting that network carriers can still be discriminatory at least among their loyal passengers from the medium and high willing to pay groups. That was the case in the U.S market until January 2005 when Delta broke down this structure.

Initially it is assumed that there is one incumbent network carrier that discriminates and one entrant that is offering discounted service between A and B only. Obviously, a new firm is not a perfect substitute for the network carrier and it can attract only a fraction of passengers from the incumbent's spectrum. The fraction of "loyal" passengers of the network airlines is the key here to find the profit maximizing pricing strategy for the network carrier. The proportions of each type of passenger who will be loyal to the network carrier are denoted by $\alpha_{H}, \alpha_{M}$ and $\alpha_{L}$. Suppose that the total demand is initially equal to $N$ where $N=n_{H}+n_{M}+n_{L}$ and $n_{H}<n_{M}<n_{L}$.

As it is stated above, the major difference of this paper from Aydin (2008) is that some fraction of each passenger type will fly with the network carrier regardless. That is, there are loyal passengers as follows:

$\alpha_{H} n_{H}:$ Number of loyal passengers in the high group

$\alpha_{M} n_{M}$ : Number of loyal passengers in the medium group

$\alpha_{L} n_{L}:$ Number of loyal passengers in the low group

The low-cost carrier already charges the discounted price, which is $p=\beta-d$. The decision here will be made by network carrier, which has two options; (1) continue to discriminate at least among the loyal passengers and share the low end pleasure travelers with the low-cost carrier or (2) match the fare of the discount airline. This study assumes that there is no capacity constraint to avoid complexity. The profit level for the network carrier can be calculated under both situations as it is shown below.

Profit under discrimination:

$\pi^{D}=(\beta+s) \alpha_{H} n_{H}+\beta \alpha_{M} n_{M}+(\beta-d) \alpha_{L} n_{L}+\frac{1}{2}(\beta-d)\left(1-\alpha_{L}\right) n_{L}-C_{C}-C_{S}$

Profit under uniform pricing:

$$
\pi^{U}=(\beta-d)\left[\frac{1}{2}\left(n_{H}+n_{M}+n_{L}\right)\right]
$$

The network carrier will choose discrimination if $\pi^{D}>\pi^{U}$ and use uniform pricing otherwise. The inequality $\pi^{D}>\pi^{U}$ holds only if

$$
\beta n_{H}\left(\alpha_{H}-\frac{1}{2}\right)+\beta n_{M}\left(\alpha_{M}-\frac{1}{2}\right)+\frac{1}{2}(\beta-d) \alpha_{L} n_{L}+s \alpha_{H} n_{H}+\frac{1}{2} d\left(n_{H}+n_{M}\right)>0
$$


The sum of the last three parts of the inequality is always positive. Hence, whether the inequality holds depends on the values of $\alpha_{H}$ and $\alpha_{M}$. If they are bigger than or equal to 0.5 , then the network carrier will discriminate even at the presence of low-cost carrier. But if $\alpha_{H}$ and $\alpha_{M}$ have low values, in other words if the network airline has very few loyal customers, the network carrier may chose to charge a uniform price.

Solving the same situation when two network carriers and one low-cost carrier are present gives us the following condition, which is very similar to (5). Condition (5) suggests that the more the network carriers in the route the more likely that the low-cost carrier will force them to drop discrimination. Solving (3) and (4) with three firms reveals that $\pi^{D}>\pi^{U}$ condition holds only if

$$
\beta n_{H}\left(\alpha_{H}-\frac{2}{3}\right)+\beta n_{M}\left(\alpha_{M}-\frac{2}{3}\right)-\frac{1}{3} \beta n_{L}+\frac{2}{3}(\beta-d) \alpha_{L} n_{L}+s \alpha_{H} n_{H}+\frac{2}{3} d\left(n_{H}+n_{M}\right)>0
$$

In a simulation created in the computer, we have found conforming results supporting our hypothesis that as the proportion of loyal customers for network carriers decreases the market will be less suitable for discrimination.

\section{CONCLUDING REMARKS}

Since deregulation, the airline industry could be considered a contestable market, although perhaps not perfectly contestable (Baumol 1982). Although point-to-point and hub-and-spoke airlines have used price discrimination since the early 1980s, its use is less extensive among point-to-point airlines. At the same time, the low rate of return on capital experienced by major network airlines is an established fact. The networks earn normal, or slightly below normal, profits. This raises the question as to why price discrimination persists in the industry, given its contestability conditions and wide differences in structure between the network and low-cost carriers.

The findings of this study support the notion that firms can effectively use price discrimination in situations where they have no control over entry, but can effectively channel consumers into market segments. Price discrimination can then be used to cover the carriers' common and separate costs. This result mainly depends on the magnitudes of $s$, which is consumers' additional utility from avoiding undesired restrictions on reduced-fare tickets, and $d$, consumers' utility loss from undesired restrictions on reduced-fare tickets, and the ratio of well-defined categories of business travelers to pleasure travelers.

From a game-theoretic perspective, it is possible that price discrimination is the result of Nash equilibrium among the network carriers. However, this may have changed recently due to increasing competition from uniformpricing, low-cost airlines that have taken market share from the majors.

\section{AUTHOR INFORMATION}

Dr. Recai Aydin is an Assistant Professor of Economics at the Turkish National Police Academy. He received his M.A and Ph.D. degrees in Economics from the University of Houston and his B.A degree in Economics from Bilkent University in Turkey. Before joining the faculty of the Turkish National Police Academy, he taught at Lamar University, Beaumont, Texas, the University of Saint Thomas in Houston, Texas, and Stephen F. Austin State University in Nacogdoches, Texas. His primary research interests are applied microeconomics, real estate, industrial organization and the economics of crime.

Dr. Roger Morefield is an Associate Professor of Economics at the University of Saint Thomas in Houston, Texas. He joined the University of Saint Thomas in 1980 and teaches undergraduate and MBA classes. Dr. Morefield received his PhD. in Economics from Duke University in 1977, an M.A. in Economics from Duke in 1975, and a B.S. in Business and Economics from the University of Alabama at Birmingham in 1972. He has authored and coauthored several refereed journal and proceedings articles. His primary research interests are environmental economics, international trade, urban and regional economics, economic education, and industrial organization. 


\section{REFERENCES}

1. Aydin, Recai. (2008), "Explaining the Persistence of Price Discrimination in the Airline Industry," The Journal of American Academy of Business, Cambridge, 13 (2), 20-27.

2. Baumol, W. (1982), "Contestable Markets: An Uprising in the Theory of Industry Structure," American Economic Review 72 (1), 1-15.

3. Berry, S., Carnall, Michael and Spiller, Pablo T. (1997), "Airline Hubs: Costs, Markups and the Implications of Customer Heterogeneity", NBER Working Paper \#5561.

4. Chapman, Ben. (2005), “ Delta Dumps Corporate Contracts”, Meeting News.com

5. Dana, James D. Jr. (1998), " Advance-Purchase Discounts and Price Discrimination in Competitive Markets", The Journal of Political Economy, 106 (2), 395-422.

6. Dirlam, J. and Kahn, A. (1952), "Price Discrimination in Law and Economics", American Journal of Economics and Sociology, 11(3), 281-314.

7. Hayes, K. and Ross, L. (1998), "Is Airline Price Dispersion the Result of Careful Planning or Competitive Forces?" Review of Industrial Organization 13 (5), 523-541.

8. Kruggel, James C. (2004), "How to Reform and Stabilize Airline Industry”, Human Events Online.

9. Lee, Darin. (2003), "An Assessment of Some Recent Criticism of the U.S. Airline Industry”, Review of Network Economics, 2 (1): 1-9.

10. Morrison, Steven A., and Clifford Winston. (1995), "The Evolution of Airline Industry, Washington D.C., Brookings Institution.”

11. Robson, John E. (1998), “Airline Deregulation: Twenty Years of Success and Counting”, Regulation, 20 (6).

12. Thierer, Adam D. (1998) " $20^{\text {th }}$ Anniversary of Airline Deregulation: Cause for Celebration, Not Reregulation", The Heritage Foundation.

13. Shy, Oz. (2001), The Economics of Network Industries, Cambridge University Press.

14. Stavins, J. (2001), “Price Discrimination in the Airline Market: The Effect of Market Concentration", The Review of Economics and Statistics, 83 (1), 200-212. 